\title{
LOS REALISTAS: HISTORIOGRAFÍA, SEMÁNTICA Y MILICIA*
}

\author{
Rodrigo Moreno Gutiérrez \\ Universidad Nacional Autónoma de México
}

\begin{abstract}
T as palabras no solo tienen historia sino que son histo_ria. El estudio de aquellos términos que se convierten en denominaciones políticas o en categorías historiográficas puede mostrar facetas reveladoras de procesos históricos tan intrincados y heterogéneos como aquel que revolucionó el mundo hispánico a comienzos del siglo xIx. Bajo dicho
\end{abstract}

Fecha de recepción: 16 de agosto de 2015

Fecha de aceptación: 3 de febrero de 2016

\footnotetext{
"Este artículo se inscribe en el marco de dos proyectos: "Las nuevas orientaciones en la historia política-intelectual. Balances y perspectivas: Argentina-México" (proyecto núm. 207486 perteneciente al Programa de Cooperacion Bilateral nivel 1 -Convocatoria 2013 Conicet-Conacyt); y "Reformas ilustradas en Hispanoamérica, una perspectiva desde la historia conceptual” (proyecto PAPIIT núm. IN401913). Una primera versión fue discutida en el coloquio "Félix Calleja y su época: crisis de la monarquía y Guerra de Independencia en Nueva España”, el 23 de febrero de 2015 en el Instituto de Investigaciones Históricas de la Universidad Nacional Autónoma de México. Agradezco a los amigos y colegas los comentarios y sugerencias recibidos desde entonces.
} 
supuesto, ¿de qué hablamos cuando hablamos de realistas? Aunque la abundante y sustanciosa historiografía contemporánea sobre los procesos independentistas iberoamericanos, en general, y novohispano, en particular, padezca una dispersión prácticamente inabarcable, parece incuestionable que existe consenso en el uso del término realista para aludir genéricamente a aquel que en sus muy distintas vertientes, etapas y latitudes se opuso a las rebeliones. Será difícil encontrar un estudio sobre cualquier fenómeno histórico relacionado con las independencias que pueda prescindir de ese otro, el realista, tan necesario para generar el contraste con el que aparezca el insurgente o el patriota e incluso el indiferente.

Una rápida revisión historiográfica sobre las independencias y en particular sobre los estudios de tema militar arrojará nutridos análisis, relatos y escritos de diverso calado sobre aquellos que, sin mayores problematizaciones y desde el título, se designan como realistas. ${ }^{1}$ Pareciera estar tan claro en términos historiográficos de qué hablamos cuando hablamos de realistas que no ha habido - salvo en contadas excepciones - una reflexión sobre el término, sus usos, implicaciones e historia.

\footnotetext{
${ }^{1}$ Algunos ejemplos: Hamnett, Revolución y contrarrevolución; Albi, Banderas olvidadas; Semprún y Bullón, El ejército realista; LuQui-Lagleyze, "Por el rey, la fe y la patria" y Luqui-Lagleyze y Manzano, "Los realistas"; SÁnchez Gómez, "La independencia”; ArCHER, "En busca de una victoria"; José Martín Hurtado Gálvez, "El ejército realista en la ciudad de Querétaro, 1810-1821”, ponencia presentada en la XIII Reunión de Historiadores de México, Estados Unidos y Canadá, Querétaro, 27 de octubre de 2010, http://13mexeuacan.colmex.mx/Ponencias/20PDF/ Jos/C3/A9/20Mart/C3/Adn/20Hurtado/20Galves.pdf, consultado el 15 de enero de 2015.
} 
En tiempos en que la historia conceptual y el estudio de los lenguajes políticos nos obligan a pensar dos veces cuando hablamos de patria, independencia, libertad, soberanía o nación, ${ }^{2}$ y que debemos ser conscientes de polisemias y ambigüedades, no solo para evitar graves anacronismos sino más aún para comprender mejor la naturaleza de las transformaciones políticas en una época revolucionaria, la voz realista no ha revelado la riqueza histórica que entraña. Estoy lejos de pretender la quiebra del que a todas luces es hoy un consenso historiográfico; por el contrario, mi ambición es más, digamos, contextualista. Es decir, dado que en la actualidad historiográfica no parece haber mayores dificultades en responder de qué hablamos cuando hablamos de realistas, en cambio, el planteamiento se enriquece sustancialmente al preguntar qué uso, utilidad e implicaciones tenía la voz realista para los actores políticos y militares del tiempo de las revoluciones hispanoamericanas. Es en ese sentido en el que suscribo a plenitud la preocupación expuesta por Javier Fernández Sebastián relativa a analizar y contextualizar las categorías con las que los historiadores (aunque no solo nosotros) clasificamos tiempos, espacios y actores históricos, tomando en cuenta, entre muchos otros elementos, la existencia de los términos (realista en este caso) en el periodo de estudio y la conciencia de los actores de aquel tiempo al utilizarlos. ${ }^{3}$

Las próximas líneas buscan, entonces, llamar la atención sobre la conveniencia de emprender dicha reflexión

\footnotetext{
${ }^{2}$ Fernández Sebastián, Diccionario y Fernández Sebastián y FuenTES, Diccionario.

3 Fernández Sebastián, “¿Cómo clasificamos a las gentes del pasado?”, pp. 115-139.
} 
con un doble objetivo. El primero consiste en desentrañar y en última instancia problematizar el término realista desde dos ángulos: por una parte, un breve recorrido historiográfico que dé cuenta de su utilización y pronta entronización práctica como categoría cerrada y, por otra, el análisis de los usos de que fue objeto dicha voz en el tiempo de las independencias. El segundo objetivo busca ofrecer algunos elementos de análisis que sean útiles para explicar el desarrollo de la estructura miliciana de las fuerzas armadas virreinales a lo largo del conflicto independentista novohispano con particular atención a aquellas que propiamente fueron conocidas en su momento como realistas.

\section{HISTORIOGRAFÍA Y SEMÁNTICA \\ HISTÓRICA DE LOS REALISTAS}

A pesar de que numerosísimos trabajos han tratado diversos aspectos de los realistas, en muy pocas ocasiones se ha analizado el uso y la historia de realista como concepto, como calificativo político o como categoría historiográfica. Uno de los pocos estudios que se han ocupado, entre otras cosas, de rastrear la construcción historiográfica del realista como ese gran otro del proceso independentista novohispano es el de Andrea Rodríguez Tapia. ${ }^{4}$ En su análisis, Rodríguez Tapia examinó las formas en las que los primeros cronistas, relatores e historiadores del temprano siglo XIX nombraron a ese conjunto de opositores a la insurgencia. Servando Teresa de Mier, Carlos María de Bustamante, Lorenzo de Zavala, José María Luis Mora y Lucas Alamán,

${ }^{4}$ Rodríguez Tapia, “Los opositores”, p. 16. 
pero también las menos frecuentadas plumas de los españoles Juan López Cancelada, Pablo de Mendíbil, Mariano Torrente y José Presas, sirvieron a la autora para delinear la paulatina construcción, siempre dual, del enemigo o, mejor dicho, del que desde el punto de vista patriótico americano fue el enemigo. Empleando herramientas propias del análisis historiográfico, Rodríguez Tapia dio cuenta de la compleja y apresurada construcción conceptual que dotó de sentido a ese universo de individuos que o no se insurreccionaron o, más aún, combatieron a los que sí lo hicieron. Dado que el protagonista forzoso de este conjunto de historias fundacionales - y prácticamente de todas las que siguieron al menos por siglo y medio - fue la insurgencia, hubo en general poca reflexión sobre el opositor que, no obstante, tenía que figurar necesariamente en los relatos. Finalmente y como sabemos, el término que quedó fijado en la historiografía para denominar a ese antagonista fue el de realista. En esa medida, Rodríguez Tapia elaboró un seguimiento historiográfico de los usos de dicha palabra pero también y por añadidura de todos los demás que sirvieron a los autores para tejer la dualidad de la guerra. Resulta significativo que la autora confesó que su primera intención había sido analizar el desarrollo de la voz realista durante los años de la guerra, pero que abandonó dicha mira al percatarse de que "su uso estaba ceñido a cuestiones de orden castrense: los 'realistas' eran los soldados y oficiales alistados en el ejército de la Nueva España, que solían recibir el mismo adjetivo".

En esa medida, llama la atención que algunos de los primeros exponentes de la historiografía de la independencia, como Bustamante, Zavala o Mora, hayan prescindido del término realista para referirse a lo que en su relato figura 
como partido español, causa española, contrarrevolución, servidumbre, dependencia, tiranía o, simplemente, “enemigos de nuestra independencia”. Como bien señaló Tomás Pérez Vejo en un reciente análisis sobre las polarizaciones ocasionadas por la guerra, solo después de consumadas las independencias se volvió habitual “español como categoría que va más allá del lugar de nacimiento, los enemigos seculares de los americanos y de su libertad [...] pero no podemos tomar como causa lo que sólo es la consecuencia del desarrollo del propio conflicto bélico" ${ }^{5}$

En efecto, la operación historiográfica no fue menor. Pasadas las décadas, el resultado final consistió en la consolidación de un gran bloque homogéneo que por diversas razones se empeñó en favorecer a los gobiernos virreinales y, por tanto, en la continuación del vínculo con la metrópoli. En la Historia de Méjico, de Lucas Alamán, sea por caso, ya aparecen las partes beligerantes claramente identificadas como bando (o partido o causa) realista y bando insurgente. Todos aquellos que integraron dicho bloque fueron los realistas. Como puede observarse, la historiografía ofrece un camino para entender esta suerte de tergiversación o trasvase; otro, que nos acerca con mayor puntualidad a los usos del término en los años del conflicto, es el estudio del léxico político y la semántica histórica.

Ya contamos con aportaciones valiosas que se han ocupado de examinar el léxico político empleado en los años de conflicto para referirse al respectivo enemigo. En este sentido resulta en particular atractiva la aportación de Moisés Guzmán en un reciente artículo en el que estudió los

5 Pérez Vejo, “Un mito historiográfico”, p. 89. 
sistemas de representación creados al calor del conflicto y la forma en que éstos enfatizaron las diferencias entre bandos que, en principio, peleaban supuestamente por lo mismo (rey, religión y patria). Guzmán se preguntó entonces cómo se pensaron las colectividades, cómo se construyó la imagen del otro y cómo repercutieron los imaginarios políticos $^{6}$ en la conformación de identidades. En este caso Guzmán analizó los términos chaqueta, insurgente y callejista o acallejado para explicar los complejos juegos simbólicos de autoidentificaciones y descalificaciones con que los grupos buscaron, por medio de las palabras, legitimar y socializar sus proyectos al tiempo que desacreditar los del rival. En los "chaquetas" surgidos en torno al golpe a Iturrigaray en 1808 y relacionados con los Voluntarios de Fernando VII, Guzmán encontró el germen de ese "partido europeo" que aglutinó desde entonces tanto a ricos peninsulares cuanto a los partidarios del gobierno monárquico, progresivamente mejor agrupados como opositores a las posteriores insurgencias política y popular.

Por su parte, Richard Hocquellet estudió en uno de sus últimos artículos la fuerza discursiva y el potencial político de la injuria y las invectivas en un momento de crisis como lo fue el de la España invadida por Napoleón. Hocquellet encontró que apelativos como servil no fueron necesariamente peyorativos e incluso llegaron a ser reivindicados en

\footnotetext{
${ }^{6}$ Guzmán entiende por imaginarios políticos las "diferentes formas en que un grupo humano se piensa a sí mismo e imagina a su colectividad respecto a las autoridades que lo gobiernan, a su régimen político, a los límites de su poder y a las bases de su legitimidad. Pero también, a las ideas y proyectos que de palabra o por escrito, se empeñan en difundir y socializar hasta hacerlos realidad". Guzmán, "Chaquetas", p. 136.
} 
el Cádiz de las Cortes para aludir al vasallo fiel y "servidor del rey y de la religión". ' Según el historiador francés, servil cayó en desuso cuando Fernando regresó en 1814, triunfal y absolutista, y en cambio comenzó a circular con mayor enjundia, en esa España restaurada, el término realista. El uso de algunas designaciones como estas volvería a complicarse y a resignificarse tras el restablecimiento de la Constitución en 1820, mutación política que habría acarreado la reaparición en la palestra pública de los serviles y el surgimiento de su derivado servilones.

Respecto a la historia y el uso del término realista, María Teresa García Godoy, en un estudio más lexicográfico que histórico, aventuró la hipótesis de que dicha voz no sólo aludía a los partidarios del rey sino que en Nueva España y en toda la América española designaba también "la tendencia política mayoritaria de los españoles afincados” ahí, "esto es, a los simpatizantes de la política absolutista del virrey, tibiamente remozada por la promulgación de la Carta gaditana"; "podríamos decir [concluye García Godoy] que realista es la expresión política de gachupín, sólo que mientras en éste prima la nota del nacimiento, en aquél se destaca el rasgo de afinidad política".

Conviene complementar este breve panorama con un vistazo a los diccionarios históricos. ${ }^{9}$ En principio es interesante destacar que el término realista no aparece ni en el Tesoro de la lengua castellana publicado por Sebastián de

\footnotetext{
7 Hocquellet, "Nombrar al enemigo", pp. 261-270.

${ }^{8}$ García Godoy, Las Cortes, p. 298.

9 Resultados del lema realista en la base de datos Nuevo Tesoro Lexicográfico de la Lengua Española: http://buscon.rae.es/ntlle/SrvltGUILoginNtlle [consultada entre febrero y junio de 2015].
} 
Covarrubias en 1611 ni en la primera edición del Diccionario académico (mejor conocido como Diccionario de autoridades), que apareció entre 1726 y 1739, como sí lo hace, en cambio, en el diccionario francés-español de Francisco Sobrino de 1705, en donde encontramos como definición de realista "los que son del partido del Rey". En ese mismo sentido, Esteban de Terreros y Pando definió realista en su Diccionario castellano de 1788 como "el que defiende los derechos del Rei, sigue sus partes, ó milita debajo de su bandera". No fue sino hasta 1803 cuando apareció la voz en el diccionario académico con dos acepciones: "el que en las guerras civiles sigue el partido de los reyes" (Regiarum partium sectator), con la observación de que se trataba de un adjetivo que también se usaba como sustantivo; y como "el que defiende las regalías, derechos y prerogativas [sic] de los soberanos" (Potestatis regiae defensor). Como queda claro, todas las definiciones se referían, en suma, a la defensa del rey y de su ejercicio del poder. Desde la edición de 1803 la definición presentó pocas variantes a lo largo del siglo XIX y mantuvo la acepción de "el que sigue el partido del rey". ${ }^{10}$

Este apretado recorrido léxico no deja muchas dudas sobre el sentido con que fue utilizado el término en el ámbito español. Un vistazo tanto a la prensa española de la época de las independencias cuanto a la historiografía española

${ }_{10}$ Cabe señalar que el término regalista es de aparición mucho más tardía que realista y supuso la defensa de las prerrogativas regias o la jurisdicción del rey frente a ámbitos o corporaciones como la Iglesia. En ese sentido, José María Portillo Valdés sugiere que podría establecerse un contraste entre el tipo de defensa regia que implica el regalismo, respecto al realismo como postura en particular notoria en momentos de crisis política o dinástica. 
relativa al reinado de Fernando VII corrobora el uso de realista para referirse, en general, al partidario de la monarquía absolutista y, en particular, al partidario del gobierno absolutista de Fernando VII. ${ }^{11}$ Si bien se pueden documentar algunos casos en los que el término figura antes de 1814, es claro su incremento a partir de entonces, cuando el monarca regresa y abole el régimen constitucional gaditano. De ahí en adelante lo realista será no solo políticamente correcto y aceptado sino, en términos del régimen establecido, efectivamente gobernante. Como dato curioso pero significativo, uno de los bergantines de correo que unían España y América en 1818 tenía el nombre Realista. ${ }^{12}$

No obstante, la voz realista irrumpe en la palestra pública y en cierto modo determina los debates y la configuración de las facciones a partir del restablecimiento de la Constitución gaditana en 1820. A decir de Emilio La Parra, durante el llamado Trienio Liberal (1820-1823) los otrora serviles

[...] se calificaron a sí mismos de 'realistas', eso es, amantes o partidarios fieles y firmes del rey. Abogaban, ante todo, por la continuidad de la monarquía absoluta, pero no se dijeron 'absolutistas' porque no se consideraban ni un partido o grupo, ni, por supuesto, una facción, sino los auténticos y únicos españoles religiosos y leales a la institución monárquica. En su opinión, sólo había una forma de gobierno: la monarquía encarnada por un rey paternal dotado de plenos poderes, cuyos actos se ajustaban a la doctrina de la religión católica. Toda alteración de ese sistema, en particular las teorías sobre la división de poderes y la soberanía nacional, era producto de la

11 Artola, La España de Fernando VII, pp. 558 y ss.

${ }_{12}$ Diario mercantil de Cádiz (21 ago. 1818). 
revolución y un atentado al orden divino; la anarquía, en suma, porque implicaba la ausencia de gobierno justo, causaba desorden, atentaba contra la propiedad y daba pie a la movilización del populacho. Además de 'anarquistas', los constitucionales eran 'republicanos', pues defendían una Constitución que de hecho impedía al rey ejercer sus prerrogativas. ${ }^{13}$

En efecto, a lo largo de la conflictiva restauración constitucional los realistas figuraron como tendencia beligerante que pugnó por la restitución de la monarquía absolutista de Fernando VII que, a su modo de ver, se mantenía cautivo por los desenfrenados liberales que habían usurpado lo que por derecho natural y divino le correspondía al único y verdadero soberano. Como es sabido, esa tendencia resultó triunfante en 1823 debido, entre otros factores, a la intervención militar francesa. De nueva cuenta Fernando VII pudo gobernar libre de ataduras constitucionales. Fue durante ese régimen, historiográficamente conocido como la "década ominosa”, cuando la voz realista alcanzó su auge definitivo pues, de nueva cuenta, se convirtió en la tendencia política hegemónica. El fenómeno que mejor retrató el uso de dicha voz fue la aparición del cuerpo miliciano de Voluntarios Realistas, fuerza que estuvo llamada a suplantar a la constitucionalista Milicia Nacional, que se había convertido en blanco de todas las inquinas y sospechas fernandinas. El origen de los Voluntarios Realistas tuvo lugar en plena invasión francesa y su alistamiento lo decretó el Duque de Angulema, jefe de la expedición bautizada los Cien Mil Hijos de San Luis. En el primer artículo del decreto el príncipe francés

${ }^{13}$ La Parra, Los Cien Mil, p. 73. 
consignaba que todos los vecinos y naturales de los pueblos de entre 20 y 50 años de edad podrían ser admitidos como Voluntarios Realistas siempre y cuando concurrieran en ellos "las circunstancias de buena conducta, honradez conocida, amor a nuestro soberano, y adhesión decidida a la justa causa de restablecerse en su trono, y abolir enteramente el llamado sistema constitucional, que tantos males ha causado a toda la Nación y a sus individuos". ${ }^{14}$ La importancia de esta peculiar milicia, absolutista y fernandina, quedó plasmada, por ejemplo, en el episodio nacional que Benito Pérez Galdós tituló Un voluntario realista, relato que narra la vida del catalán Pepet Armengol y que se ocupa, entre otras cosas, de la represión de que fueron objeto los liberales a manos de la colérica reacción realista.

No resulta extraño, entonces, que historias y relatos sobre las independencias hispanoamericanas que vieron la luz en dicho contexto español, como la de Mariano Torrente, hayan utilizado el término "ejércitos realistas", puesto que interpretaban el conflicto ocurrido la década anterior en América como una proyección de la escena política peninsular entonces vigente. En ese orden de ideas, los "buenos realistas" o los "verdaderos realistas" correspondían a los que, como en su España de 1830, combatían en favor de la causa del rey. ${ }^{15}$

14 Pérez Garzón, Milicia nacional, p. 344.

15 Torrente, Historia. 


\section{Gráfica 1}

USO DE LAS VOCES REALISTA Y REALISTAS ENTRE 1800 Y $1840^{16}$

$\begin{aligned} & \% \\ & 0.0130 \\ & 0.0120 \\ & 0.0110\end{aligned}$
0.0100

Los ritmos del uso de la voz realista quedan claramente expresados en la gráfica 1 que, si bien es cierto que incluye todo tipo de impresos en español, refleja con fidelidad los compases políticos de la España peninsular. En efecto, como lo convalida la revisión hemerográfica e historiográfica específica del ámbito peninsular, se puede observar que: 1) el término fue de uso excepcional antes de 1812 (por ejemplo, resulta sumamente significativo que una de las pocas referencias de 1811 es un impreso que habla de los realistas de la época de la revolución francesa para referirse a los monárquicos

${ }^{16}$ Gráfica elaborada mediante la búsqueda combinada de los términos realista y realistas en la muy útil herramienta Google books Ngram viewer que, como se sabe, rastrea en el corpus de fuentes en español disponibles en la base de Google books (impresos de diverso tipo: libros, hemerografía, folletería) en el rango cronológico elegido (eje horizontal de la gráfica): 1800 a 1840. El eje vertical indica el porcentaje de aparición de los términos realista y realistas en la totalidad de obras del corpus de Google books. En este caso se eligió un smoothing o promedio de 1 para poner en evidencia la tendencia: https://goo.gl/kVuAZl [consultada el 15 de diciembre de 2015]. 
y opositores a los proyectos constitucionales ${ }^{17}$ y poco usual entre 1812 y 1814; 2) que con el retorno absolutista su uso fue aceptado pero no por ello generalizado; 3) que aumentó considerablemente durante el Trienio Liberal, reivindicado por unos (carga positiva) y denostado por otros (carga negativa), más aún cuando se hablaba de "ultrarrealistas"; y 4) que su apogeo ocurrió entre 1823 y 1833, durante el régimen absolutista que Fernando VII mantuvo hasta su muerte. Dicho apogeo se explica por el deliberado empeño del gobierno y la prensa fernandistas por enfatizar su impronta realista que en ese contexto subrayaba la lealtad y la obediencia irrestrictas al rey, como bien lo ejemplifican los Voluntarios Realistas pero también, sea por caso, los himnos realistas dedicados a Fernando y que cantaban, por ejemplo:
Al Rey amenazan
con grito feroz
diciendo que jure
la Constitucion.
Le ponen puñales

17 Alvarado, Cartas críticas, pp. 101-102: “Al órden del dia fue la res-
puesta del señor no sé si Mirabeau, si Pethion, ó si algun otro de los gran-
des hombres que la familia del Conciso nos cita; y las monjas, á pesar
de estar declaradas libres, fueron arrojadas de su convento. Se declaró la
libertad de opinar en punto de religion y de política, declarando igual-
mente por religion dominante la católica, por gobierno de la nacion el
monárquico, y por temperamento el de la constitucion. A los seis meses
ya no habia en el pueblo libre para opinar, quien se atreviese á hacerlo por
la religion dominante, y poco tiempo despues el que se descuidaba en san-
tiguarse donde lo viese algun soplon, iba sin remedio á la guillotina. La
misma suerte siguió á los realistas desde el momento en que el gobierno
se declaró monárquico: y en la misma vinieron á parar antes de dos años
los que reclamaron la constitucion y aristocracia”. Las cursivas son mías. 


$$
\begin{gathered}
\text { al pecho ique orror! }[\text { sic }] \\
\text { y quitan al trono } \\
\text { todo su esplendor... }
\end{gathered}
$$

El seguimiento de la voz realista se vuelve más problemático en este lado del Atlántico puesto que, sin invalidar los sentidos, implicaciones y significados aceptados en España, el término adquirió por una parte nuevos matices y, por otra, usos más concretos. Otra revisión, esta vez de la documentación de la Nueva España y la prensa de la época, ${ }^{19}$ corrobora de manera aproximada los ritmos de uso que dejó ver el panorama peninsular. Así, antes de 1812 es prácticamente inexistente la voz en los registros documentales novohispanos, pero a partir de entonces su uso aumenta de manera paulatina y con un sentido distinto al peninsular pues aludía, en construcción dualista, a la oposición y los opositores de los insurgentes que, por cierto, desde entonces comenzaban a ser referidos así (además de rebeldes, sublevados, facciosos, insurrectos, etc., desde el punto de vista del gobierno, y patriotas o americanos, desde la propia insurgencia).

18 Meseguer, Himno Realista, p. 15. Otro ejemplo muy ilustrativo es el de una "Canción realista americana", presumiblemente fechada en 1824 y cuyas estrofas versaban: "Los negritos de la Havana / le dicen al Rey Fernando: / que aunque su color es negro, / para amarle son mui blancos. / Tambien cantan los negritos, de Realistas blasonando: / si en España hay blancos-negros, / en la Habana hay negros-blancos. / Por librar al Rey Fernando / de las furias liberales, / se han armado los Realistas / de espadas y no puñales...": El solo por eso, p. 3. Por Gil Novales sabemos que "blanco" equivalía en aquellos años a "realista". Gil Novales, Las sociedades patrióticas, t. II, p. 975.

${ }^{19}$ Fundamentalmente realizada en la Gaceta del Gobierno de México (1808-1821) y en Hernández y Dávalos, Colección. 
En términos generales la búsqueda arrojó las siguientes impresiones: 1) el término realista fue mucho más socorrido por los insurgentes que por las fuentes oficiales del gobierno virreinal o los partidarios de éste, aunque sí existen algunas muestras de su uso reivindicativo; ${ }^{20} 2$ ) en las fuentes insurgentes o en los testimonios tomados a insurgentes, el realista (ya como individuo, ya como "partido") aludía a aquel que favorecía al gobierno virreinal o pertenecía a éste; y 3 ) a partir de 1815 aparece con fuerza inusitada en la documentación oficial (tanto la publicada en la Gaceta cuanto la cruzada entre autoridades políticas y militares) para referir exclusiva y precisamente a un tipo de fuerza miliciana. Justamente es este fenómeno al que dedico el siguiente apartado.

\section{LAS MILICIAS NOVOHISPANAS DURANTE LA GUERRA:} VOLUNTARIOS, PATRIOTAS, URBANOS Y REALISTAS

El problema miliciano en el contexto de las revoluciones independentistas hispanoamericanas en general, y novohispana en particular, ha sido abordado desde distintos ángulos en la historiografía que de muchos modos se ha ocupado de temas militares y que abarca desde las obras clásicas de Lyle McAlister y Günter Kahle, hasta las más recientes de Juan Marchena, Allan Kuethe, Christon Archer y Juan Ortiz. ${ }^{21}$

20 Por ejemplo la respuesta de Ignacio Elizondo a Bernardo Gutiérrez de Lara, en territorio texano, en abril de 1813, en la que a diferencia del homicida y traidor, como tildaba a Gutiérrez, Elizondo se consideraba un defensor de la religión y un "realista y patriota decidido”. Hernández y DÁvalos, Colección, t. IV, doc. 230.

21 McAlister, El fuero militar; KAHLE, El ejército; MARCHENA, El ejército de América; Kuethe, "Las milicias"; Archer, El ejército; Archer, 
En adición, en los años más cercanos han visto la luz estudios dedicados específicamente a diversos aspectos milicianos, como las obras de Ben Vinson III, Juan José Benavides, José Antonio Gutiérrez, Jesús Mendoza Muñoz, ${ }^{22}$ así como varios artículos de libros colectivos. ${ }^{23}$ Dado que se trata de un fenómeno que demanda un estudio mucho más amplio, aquí me ceñiré a ofrecer algunas observaciones relativas a los términos empleados para hacer referencia a las distintas fuerzas milicianas, tomando en cuenta, como es bien sabido, que éstas representan literalmente un mundo paralelo al de las fuerzas armadas regulares, veteranas o de línea, que cuenta con una estricta y profusa reglamentación.

Justamente apegándonos a la reglamentación vale la pena notar que las ordenanzas que normaron a las fuerzas armadas desde el siglo XviII hablan tanto de milicias provinciales, ${ }^{24}$ regladas y urbanas, cuanto de milicias o voluntarios de infantería y caballería (con distintas características en función de la composición y ubicación de sus batallones o regimientos) para referir a esos novedosos cuerpos de súbditos no profesionales de las armas que se debían incorporar a las tareas de defensa de los dominios del rey en forma de ejército de reserva a disposición de la estructura militar en situaciones o momentos extraordinarios. Es

"The Army”, "Where Did All the Royalists Go”, “'La Causa Buena”; ORTIz, Guerra y gobierno.

22 Vinson, Bearing Arms; Benavides, De milicianos; Gutiérrez, El gobierno de frontera; Mendoza, Los dragones.

${ }^{23}$ Ortiz (coord.), Fuerzas militares; Kuethe y Marchena, Soldados del Rey; Chust y Marchena, Las armas de la nación y Ruiz Ibáñez, Las milicias.

${ }^{24}$ Oñate Algueró, Servir al Rey. 
interesante considerar el término voluntarios (que evidentemente explicitaba uno de los requisitos para la integración de estos cuerpos), ya presente en el pionero "Reglamento de Milicias de Cuba” sancionado por Carlos III en 1769 y que abriría la brecha para la formación miliciana en América. ${ }^{25}$

Como ha explicado con profusión la historiografía correspondiente, la estructuración de las milicias en Nueva España fue dificultosa, por no decir desastrosa. Aun así, el virreinato contaba en 1808 con milicias provinciales de caballería, milicias provinciales de infantería, compañías de milicias sueltas y milicias urbanas de infantería y de caballería; así como con algunas compañías fijas de blancos y pardos libres de las costas, y con las compañías presidiales que también podrían considerarse fuerzas milicianas. En este escenario, el advenimiento de la crisis política de la monarquía en 1808 provocó en la Nueva España, como en otras latitudes, el surgimiento de los "Voluntarios de Fernando VII". Aunque hace falta dar seguimiento puntual a estos cuerpos milicianos, baste por ahora con señalar que fue un impulso muy expandido, hasta cierto punto espontáneo y fundamentalmente urbano. Se tiene documentada su aparición en ciudades como San Luis Potosí, Querétaro y por supuesto México. ${ }^{26}$ Como recién señalé, el término voluntario no era ninguna novedad en el ámbito miliciano, pero su vinculación al nombre de Fernando VII buscó explicitar la fidelidad

25 Para una sugerente síntesis del problema miliciano antes y después del reglamento cubano véase MorelLI, “¿Disciplinadas o republicanas?”, pp. 417-436.

26 Para San Luis Potosí, Benavides, De milicianos, p. 266; para Querétaro, Mendoza, Los dragones, p. 83; para México, Pérez Márquez, "Milicia urbana”, pp. 5-11. 
americana al borbón preso por Napoleón. En México los Voluntarios de Fernando VII fueron disueltos poco después del golpe al virrey José de Iturrigaray, durante el gobierno del impuesto Pedro Garibay. Luego, cuando Francisco Xavier Venegas asumió el gobierno virreinal, y con la expresa intención de hacer frente a la rebelión recién estallada por Miguel Hidalgo en el Bajío, se encargó de restablecer a los Voluntarios con el nombre de "Batallones Patrióticos Distinguidos de Fernando VII" "27 cuerpo que en lo sucesivo sería también aludido como "patriotas distinguidos" o simplemente "patriotas".

De esta forma, Venegas - quien acarreaba consigo los dos años de la guerra contra el francés en la Península, conflicto en el que ya habían entrado en acción (además de voluntarios) distinguidos y patriotas - introdujo al ámbito miliciano de la Nueva España las denominaciones de "patriotas" y "distinguidos", términos que comenzaban a proliferar en distintos espacios de la monarquía española (no solo entre las milicias) y con sentidos ambiguos; baste con recordar los movimientos juntistas en la América meridional. El primer término, patriota, buscaba monopolizar uno de los pilares de la triada por la que todos, en principio, luchaban: rey, religión y patria, pero que en otras latitudes ya comenzaba a ser disputado y resignificado; el segundo intentaba limpiar la reputación con que cargaron los Voluntarios por su participación en el golpe a Iturrigaray y los excesos cometidos por éstos los días posteriores. Como lo explicó Servando Teresa de Mier pocos años después:

27 Bando del virrey Venegas en Gaceta extraordinaria del Gobierno de México, 5 de octubre de 1810. 
Baste decir que el mismo Garibay que les debia [a los Voluntarios] su elevacion se vió precisado á licenciarlos luego, y que ellos abandonaron sus chaquetas como un sanbenito ignominioso. Propuso Yermo á Venegas restablecerlos contra los insurgentes con el mismo nombre y vestuario que algunos conservaban en sus casas, y este Virey le respondió, bastaría la chaqueta para que los matasen las tropas mismas del rey, y el nombre de voluntarios para merecer la pública execracion: llaméseles [sic] patriotas $^{28}$

En realidad el bando de Venegas no logró desterrar el término voluntarios, simplemente agregó al universo miliciano las otras dos voces que, en efecto, se hicieron más comunes. Quizá el cambio consistió en que, a diferencia de otros lugares como Perú y Chile, en que hubo cuerpos de "voluntarios distinguidos", 29 en Nueva España pervivieron "voluntarios” en algunas comunidades, a la par que surgían "patriotas distinguidos" y "patriotas" en otras tantas.

Ya con la revolución insurgente desatada es más difícil dar seguimiento a la evolución de los cuerpos milicianos $y$, aunque contamos con algunos estudios monográficos, hacen falta análisis integrales sobre el desarrollo de las distintas milicias en cada una de las regiones afectadas por la guerra. Es muy probable que bajo el esquema de "patriotas” impulsado por Venegas y sus principales comandantes se hayan comenzado a formar cuerpos milicianos en otras regiones. Por ejemplo, Jesús Fidel Hernández Galicia documenta que José de la Cruz organizó batallones milicianos prácticamente desde que entró en acción (recordemos

${ }^{28}$ Guerra, Historia, t. I, p. 199.

29 Luqui-Lagleyze y Manzano, “Los realistas”, pp. 35-61. 
que arribó a Nueva España con el virrey Venegas) e incluso antes de establecerse en la Nueva Galicia, en lugares como Huejutla, Yahualica, Pachuca, Tetepango e Ixmiquilpan, y que en otros como Huichapan habría formado destacamentos volantes que tenían la finalidad de impedir reuniones revolucionarias. ${ }^{30}$ Félix María Calleja, por su parte, con independencia de las milicias provinciales que había logrado disciplinar y ordenar desde su llegada a San Luis Potosí y de los Voluntarios reclutados desde 1808, reaccionó a la revolución de Hidalgo con la formación de los "Fieles del Potosí”, de un "Cuerpo de Patriotas de San Luis” y, en fechas tan tempranas como octubre de 1810, de distintos cuerpos de "Urbanos Patriotas Distinguidos de Fernando VII" para el resguardo de la ciudad de San Luis, que de muchos modos anticipaban una estrategia más amplia. ${ }^{31}$

Al respecto, todo parece indicar que el fenómeno miliciano se desarrolló de manera definitiva con el célebre Plan Calleja. Aunque existen diferentes versiones e interpretaciones, resulta aceptable que el "Reglamento político-militar que deberán observar, bajo las penas que señala, los pueblos, haciendas y ranchos, a quienes se comunique por las autoridades legítimas y respectivas; en el entretanto que el excelentísimo señor virrey de estos reinos, a quien doy cuenta, se sirva hacerlo extensivo a todas las provincias si lo tuviere a bien", 32 fue dado a conocer por el entonces mariscal de campo Calleja en Aguascalientes el 8 de junio de 1811. Como bien lo ha explicado Juan Ortiz, ${ }^{33}$ el Reglamento o Plan fue

30 Hernández Galicia, “Guerra sanguinaria”, pp. 98-122.

31 Benavides, De milicianos, pp. 288-293.

32 AGN, IV, c. 1695 , exp. 5.

33 Ortiz, Guerra y gobierno, pp. 132-143. 
la respuesta de Calleja al nuevo escenario bélico de la Nueva España. La fragmentación o, como decía Calleja, reducción de la insurrección a un impolítico, bárbaro y absurdo estado de gavillas compuestas por ladrones, lo había orillado a establecer por su parte y a proponer al virrey Venegas este "plan de pacificación". En principio, el proyecto estaba destinado a permitir que las divisiones de los ejércitos regulares se dedicaran a la destrucción de los contingentes más importantes de rebeldes, toda vez que cada ciudad, villa o cabecera de partido debía defenderse por su propia cuenta mediante la formación de un "cuerpo urbano de caballería o infantería” compuesto por todos los vecinos honrados según su clase. Esos cuerpos urbanos, dirigidos por comandantes militares y jueces reales, serían armados y sostenidos con los fondos de arbitrios provisionales de las propias comunidades o, donde no los hubiere, con contribuciones forzosas equitativas y arregladas por una comisión nombrada por el cabildo local, disposición que, como es sabido, dio vida a las llamadas “juntas patrióticas”. El mismo procedimiento debían observar las haciendas, que estaban obligadas a levantar compañías de 50 hombres dirigidos por un capitán.

De esta forma, Calleja buscaba involucrar a las comunidades en su propia defensa, militarizándolas. Todos los vecinos aptos debían convertirse en milicianos o, para ser más precisos, en "urbanos" responsables de los más inmediatos destinos de la guerra. En pocas palabras y siguiendo a Ortiz, la importancia del Reglamento era fusionar los mandos civil y militar, involucrar por igual a toda la población (no solo "voluntarios" o "distinguidos") y permitir la elección de los oficiales mediante votación. Además el Reglamento incubaba una potencial cuota de autonomía en los pueblos pues 
no solo colocaba - legalmente - en las manos comunitarias los cuerpos armados sino un mecanismo para financiarlos que, aunque a la larga sería gravosísimo, implicaba (como lo ha visto José Antonio Serrano) un irrefrenable proceso de ruptura de jerarquías territoriales. ${ }^{34}$ Ayuntamientos o juntas patrióticas podrían tomar las riendas de sus comunidades mediante el control de las armas y de los dineros.

Me interesa destacar un aspecto que, en comparación con los anteriores, parecería marginal: el Reglamento políticomilitar habla de "urbanos". Como hemos visto, este término empleado para las fuerzas milicianas ya existía, e incluso había urbanos en la Nueva España antes del proyecto callejista (concretamente en México y en Puebla), pero desde la aplicación del Plan proliferaron estos nuevos "urbanos”, digamos que comunitarios y plenamente dispuestos para la guerra interior. Es cierto que la puesta en marcha del llamado Plan Calleja debe ser más cuidadosamente estudiada; empero, parece incuestionable que el mariscal sí lo hizo cumplir en sus respectivas y sucesivas jurisdicciones antes de convertirse en virrey. Aunque autores como Ernesto Lemoine han sostenido que Venegas prestó nula atención a la propuesta de Calleja, ${ }^{35}$ las más de 200 compañías

34 SERRANO, Jerarquía territorial, pp. 83-113.

35 Si bien la primera versión que Calleja circuló fue fechada en Aguascalientes el 8 de junio de 1811. Hernández y Dávalos, Colección, t. III, doc. 44, habría que recordar que Lemoine rechazó que fuera puesto en marcha: "Venegas, nada propenso a que le señalaran rumbos, arrojó el Plan al cesto de la basura, de donde lo extrajo Calleja tan pronto como se arrellanó en el sillón virreinal, abreviándole sólo el encabezado y poniéndole la nueva fecha de 5 de marzo de 1813". Lemoine, Morelos, p. 272; hipótesis que, por cierto, explicaría por qué Morelos reaccionó el 7 de junio de 1813 dictando desde Acapulco un contraproyecto que 
de patriotas y urbanos (y voluntarios) organizadas entre junio de 1811 y marzo de 1813 que Juan Ortiz registra parecen despejar las dudas. ${ }^{36} \mathrm{El}$ mismo Ortiz interpreta que el Reglamento se esparció y se instrumentó de la mano de los principales jefes militares en cada una de las regiones involucradas, verbigracia Agustín de Iturbide y Antonio Linares en Guanajuato, José de la Cruz y Pedro Celestino Negrete en Nueva Galicia, Ciriaco de Llano en Puebla y Veracruz, José Gabriel Armijo en el sur, entre otras.

Desde luego que estudios regionales ampliarían nuestra comprensión de la expansión de estos cuerpos y dejarían ver importantes matices y diferencias. No todos los jefes tenían el mismo entendimiento de la guerra y de las estrategias para abatir al enemigo. Hernández Galicia recuerda las reticencias que ya desde entonces tenía De la Cruz respecto a Calleja y sus proyectos. El que a la postre sería el mandamás de la Nueva Galicia puso en duda la viabilidad y eficiencia del plan pues creía que era aplicable en otros tiempos, cuando "la rebelión estuviera reducida a cuadrillas de 50 o 100 hombres". De la Cruz sostenía que "las compañías patrióticas en los pueblos casi de nada sirven y unidas a cualquier división hacen muy buen servicio”. Aun así observó el plan

- declarando a Calleja "nuestro enemigo común" - obligaba (entre otras cosas) a todos los hombres útiles a armarse y presentar combate en el contorno de su ubicación y dividía a los labradores en "tropa viva o veterana y urbana. Tropa viva se reputa aquella que está siempre al frente del enemigo o guardando alguna plaza conveniente al frente o fronteriza; y las urbanas son aquellas que están destinadas a la seguridad de las poblaciones y deben tener alistadas los subdelegados". Más adelante el caudillo insurgente refiere dichas fuerzas como "milicias urbanas" y especifica las armas para cada caso. Lemoine, Morelos, pp. 331-335.

36 OrTIZ, Guerra y gobierno, pp. 144-156. 
y para 1812 reportó que consideraba muy urgente "organizar el crecido número de patriotas con que cuento". ${ }^{37}$

Es de suponerse que el Plan cobró un impulso mayúsculo cuando Calleja tomó posesión como virrey, como consta por la publicación y circulación del Reglamento (prácticamente sin modificaciones respecto al original hidrocálido de 1811) el 5 de marzo de 1813, es decir, al día siguiente de haber tomado posesión.

En todo caso, cabe destacar que durante todo este periodo (1811-1815) se siguió hablando tanto de patriotas cuanto de urbanos, de ahí que las más de las veces las contribuciones que los sostenían fueran calificadas como "patrióticas", lo mismo que las juntas establecidas para administrar dichos fondos. Entonces, ¿cuándo y cómo cambiaron las denominaciones? Javier Fernández Sebastián ha encontrado en los agitados momentos del liberalismo gaditano una tentación por "gobernar el diccionario", una búsqueda por ejercer el "supremo derecho a definir" y una disputa por la legislación sobre el uso de las palabras, en el entendido de que la de aquellos tiempos fue también, de algún modo, una revolución conceptual. ${ }^{38}$ Creo que esa es la perspectiva para entender el bando que emitió el virrey Calleja el 24 de mayo de $1815^{39}$ en que condenaba enérgicamente la "ridícula" Constitución de Apatzingán. Se trata, el de Calleja, de un documento que escandaliza al tiempo que fascina desde el punto de vista de la semántica histórica, y es oportuno analizarlo

37 Oficio de De la Cruz a Venegas, Guadalajara, 12 de marzo de 1812, citado por Hernández GAlicia, “Guerra sanguinaria”, p. 165.

38 Fernández Sebastián, “La crisis de 1808”, pp. 105-133.

39 Publicado en la Gaceta del Gobierno de México al día siguiente (25 mayo 1815). 
con detenimiento pues expresa con transparencia los impulsos del absolutismo restaurado por Fernando VII.

En dicho bando Calleja habla de Apatzingán como el momento en que de una buena vez los rebeldes se quitaron la máscara con que pretendían alucinar incautos y por fin se mostraban como lo que verdaderamente eran, es decir, "traidores descarados negando resueltamente obediencia al rey nuestro señor, declarando la independencia de la Nueva España y atacando con escándalo las prácticas y derechos de la Iglesia", forjando "una especie de sistema republicano bárbaramente confuso y despótico en substancia” mediante "un compuesto de retazos de la constitución anglo americana y de la que formaron las llamadas cortes extraordinarias de España”, y todo, decía el virrey, justo en el tiempo en que españoles de uno y otro hemisferio se mostraban solícitos a recibir con entusiasmo los decretos y resoluciones del rey que anulaban las "innovaciones democráticas de las abolidas cortes de España”; pero no, en cambio, aquellos rebeldes se atrevían a circular esa constitución infinitamente más monstruosa y descabellada, "absolutamente depresiva de los derechos de Su Majestad y de todos los monarcas del mundo". En vista de todo ello, y en conformidad con el voto consultivo del Real Acuerdo, Calleja ordenaba una serie de providencias que pasaban por la censura (quema en plaza pública y en mano de verdugo de todos aquellos papeles insurgentes), el deslinde (que todas las autoridades provinciales y locales dieran testimonio público de no haber enviado diputados al llamado congreso mexicano, para desengaño de españoles y extranjeros $)^{40}$ y las palabras:

40 "Dado que los rebeldes (en el delirio de suponerse depositarios de la 
5. En todos los procesos, y en todo papel ó acto oficial en lugar de los nombres insurreccion é insurgentes, que por lo pasado se ha dado á estos monstruos, se usará precisamente en lo sucesivo, tanto de palabra, como por escrito [los] de los propios que corresponden a su delito, que son los de rebelion, traicion, traidores y rebeldes.

6. Igualmente la denominación de patriotas que hasta ahora han tenido los leales que han sabido conservar su honor y mantenidose adictos á la causa del rey nuestro señor, tomando las armas para la defensa de sus derechos, y conservacion del estado, de cuya voz han abusado tambien los infames, se mudará desde hoy en la de realistas fieles, de la ciudad, villa ó lugar á que pertenezcan, y asi se llamarán en todos los despachos, nombramientos, y actos oficiales de palabra ó por escrito, principiando por los batallones, escuadrones y brigada de artilleria de distinguidos de Fernando $7^{\circ}$ de esta capital. ${ }^{41}$

Todo tenía sentido. Ya restituido Fernando a su trono y gobernando de manera absoluta, libre de las cadenas constitucionales, había que enfatizar la obediencia y la lealtad al rey y a Dios. O al rey y por lo tanto a Dios. Ser realistas mucho mejor y mucho antes que patriotas, pues la patria ${ }^{42}$ ya había sido demasiado manipulada (por no decir manoseada) por los que (para Calleja) a estas alturas se descaraban como traidores al rey y por tanto infieles y herejes.

Así, si habían proliferado, como queda dicho, los cuerpos de patriotas (y de urbanos), no podía ser del agrado del

voluntad general) fingen tener relaciones con los Estados Unidos”, decía el punto 7 .

${ }^{41}$ Gaceta del Gobierno de México (25 mayo 1815), p. 540. Cursivas en el original.

42 Ávila y Moreno, “México/Patria-Nueva España”, pp. 153-164. 
virrey que Morelos, por ejemplo, circulara papeles firmando como "el patriota de las Fronteras del Sur" ${ }^{43}$ Qué inconveniente e impráctico resultaría tener que hacer la artificiosa distinción entre buenos y malos patriotas, que para colmo llevaba al mismo punto pues ambos bandos se erigían como los buenos patriotas; ${ }^{44}$ y qué confuso que todos pelearan, en suma, por la "causa de los patriotas", infinito juego de espejos que produjo que unos y otros echaran a andar "partidas de patriotas". ${ }^{45}$ En cambio, con el nombre de "fieles realistas" el gobierno virreinal volvía a monopolizar la legitimidad del que a fin de cuentas era, otra vez, el único titular de la soberanía, el rey Fernando VII. Dado que la insurgencia institucionalizada ya había declarado la independencia y promulgado una constitución que prescindía del rey, no había lugar a las escurridizas ambigüedades de la patria o de las muchas patrias. Porque si bien la insurgencia nunca se autodenominó realista, el ambiguo fernandismo de sus primeros años resultaba incómodo al gobierno virreinal.

En efecto, con la restauración absolutista de Fernando, los serviles se transmutaron en "realistas", lavando, por decirlo así, el término. Durante el sexenio absolutista fue políticamente correcto ( $y$ rentable) ser realista en uno y otro lado del Atlántico: la palabra subrayaba la obediencia y la fidelidad al rey (absoluto), en contraste con los vergonzantes, perseguidos o exiliados liberales y constitucionales. $Y$ en contraste, también, en la Nueva España, respecto a los rebeldes y traidores a los que ni siquiera se les reconocía la honra

43 Lemoine, Morelos, p. 186.

44 Morelos exhortó a los "buenos patriotas” a formar el Congreso de Anáhuac. Lemoine, Morelos, p. 348.

45 Lemoine, Morelos, pp. 519 y 463. 
de la revolución pues ésta dejaba abierto un resquicio de legitimidad. La rebeldía y la traición, en cambio, no cabían en ningún marco ni legítimo ni legal.

El bando de Calleja fue observado en todas las provincias y se aplicó a todos los cuerpos milicianos. Tampoco quiere decir que el término no se hubiera utilizado en el ámbito miliciano antes de la publicación del bando, ${ }^{46}$ pero queda claro que a partir de entonces su uso se generalizó. El caso de la Ciudad de México resulta ilustrativo: en correspondencia con el mandato del virrey, los cuerpos de "patriotas distinguidos" se convirtieron en "fieles realistas", como lo manifestó el Conde de Agreda (uno de los nobles más involucrados en la conformación miliciana de la capital y comandante de una de las compañías) al virrey: "Con el superior oficio de [vuestra excelencia] percibí el bando relativo a las precauciones que debo tener en orden a la infame constitución y perversas máximas en los rebeldes de este reino usando desde entonces el nombre de realistas fieles en lugar de patriotas que ha tenido el cuerpo de mi mando". ${ }^{47}$

No es este el lugar para enlistar la multitud de referencias que a partir de este momento (mayo de 1815) dan cuenta de la vigencia puntual, precisa de los centenares de cuerpos de "fieles realistas" que revistieron la estructura miliciana de la Nueva España. Es cierto que la documentación se siguió refiriendo a cuerpos de patriotas y urbanos, pero no cabe

${ }^{46}$ Benavides registra el establecimiento en San Luis de un "Batallón Mixto Urbano de Fieles Realistas" en 1813, justamente en cumplimiento de una orden de Calleja ya convertido en virrey. Benavides, De milicianos, p. 358.

47 Oficio del Conde de Agreda al virrey, México, 29 de mayo de 1815, citado por Pérez Márquez, "Milicia urbana”, p. 45. 
duda de que la abrumadora mayoría de los cuerpos milicianos y los muchos que se crearon desde entonces adoptaron la nueva denominación. A guisa de ejemplo baste con un muy ilustrativo informe del virrey Juan Ruiz de Apodaca, Conde del Venadito, elaborado a principios de $1821 \mathrm{y}$ remitido a Madrid, en el que, luego de reconocer los vigentes focos de rebelión en la intendencia de México, aseguraba que el resto de los partidos se encontraban libres "y sin más resguardo que el abrigo que proporcionan los destacamentos situados en los Pueblos y Haciendas grandes, la mayor parte compuestos de Realistas sostenidos por contribuciones municipales que los mismos Pueblos se imponen". ${ }^{48} \mathrm{El}$ documento es muy significativo puesto que refiere en otros pasajes la existencia y operatividad de las otras fuerzas armadas, como el ejército regular de tropas de Su Majestad o las milicias urbanas, pero la cita anterior destaca la importancia que el virrey otorgaba específicamente a los "realistas".

Así, estos "realistas" aparecen como un fenómeno miliciano poco estudiado y con vastas y ricas posibilidades. Su proliferación, sus reglamentaciones particulares, ${ }^{49} \mathrm{su}$ composición, ${ }^{50}$ la absorción de la mayoría de los muchísimos

48 Informe del Conde del Venadito al secretario de Estado y del despacho de la gobernación de Ultramar en respuesta a la real orden del 22 de julio de 1819, México, 8 de enero de 1821, en AGI, México, vol. 1680.

49 Por ejemplo, el "Reglamento remitido por el comandante militar de Tacubaya para reorganizar sus compañías de realistas", Tacubaya, 17 de mayo de 1819. AGN, IV, c. 1949, exp. 20.

50 Uno de los pocos estudios que han profundizado en el análisis de la oficialía y de la tropa milicianas es el realizado por Benavides con los cuerpos potosinos, de los que obtiene muy interesantes datos, como por ejemplo que el miliciano promedio de los regimientos potosinos es un "hombre joven, de entre 16 y 20 años (52\%), dedicado al trabajo del 
indultados de que se pavoneó el virrey Ruiz de Apodaca, ${ }^{51}$ y sobre todo su actividad bélica y su incidencia en el control efectivo de las regiones (en detrimento de la insurgencia), son problemas que requieren análisis bien meditados y sólidamente fundamentados en la copiosa documentación existente; recordemos que según los cálculos más conservadores, las milicias de todo tipo representaron más de la mitad de las fuerzas armadas con que contó el régimen virreinal. En suma, la defensa del régimen virreinal descansaba en muy buena medida en estos cuerpos armados de los que queda todavía mucho por conocer.

En correspondencia con este apretado seguimiento de la evolución del fenómeno miliciano novohispano durante la guerra, conviene tener presente que la última y sustancial transformación ocurrió con el restablecimiento del régimen constitucional en 1820. Como he tenido oportunidad de revisar en otras investigaciones, ${ }^{52}$ la nueva puesta en marcha de la pesada maquinaria gaditana acarreó (ahora sí, no como en el periodo 1812-1814) el surgimiento de la milicia nacional. Con independencia de las trascendentales modificaciones que esta nueva fuerza supuso, baste por ahora con señalar, primero, que Apodaca publicó en

campo (44\%), mestizo (59\%), analfabeto (90\%) y soltero (80\%). Habría nacido en la región potosina (76\%), estaría avecindado en ella ( $80 \%$ ), y se habría alistado de forma voluntaria por diez o doce años en alguna localidad de la provincia (74\%)". Benavides, De milicianos, pp. 344-345.

51 Como indican OrTIz, Guerra y gobierno, pp. 226-227 y HaMnetT, Raíces, pp. 201-205, la mayoría de los muchísimos indultados que presumía el gobierno se incorporaban a estas fuerzas de milicias locales, aumentando su potencial peligrosidad. También se engrosaron las filas de los realistas por la vía de la leva forzosa (usualmente de vagos).

52 Moreno, "Las fuerzas armadas", pp. 70-114. 
septiembre de 1820 el reglamento que permitía el establecimiento de milicias nacionales en las capitales de provincia y de partido y en los demás pueblos cuyos ayuntamientos lo pidieran; segundo, que esa medida provocó la desesperada demanda de multitud de comunidades para establecer la milicia nacional con el propósito de dejar de pagar las contribuciones extraordinarias con que sostenían a sus respectivos realistas; tercero, que el gobierno hizo cuanto pudo para frenar esas demandas $y$, por tanto, mantener en pie tanto a los realistas cuanto el cobro de las contribuciones; cuarto, que en octubre de 1820 las Cortes de Madrid, con el aval de los diputados novohispanos Fagoaga, Couto, Ramos Arizpe, Cortázar, Michelena y Montoya, publicaron un nuevo reglamento provisional para la milicia nacional en las provincias de Ultramar cuyo primer artículo disponía: "Esta Milicia se compondrá por ahora de todos los cuerpos ó compañías Urbanas y demás de esta clase, que con el nombre de Realistas, Patriotas ú otro semejante existieren en las provincias ultramarinas, exceptuando las islas de Cuba, Sto. Domingo y Puerto Rico", ${ }^{53}$ suprimiendo así la quintaescencia de la milicia nacional ideada por los liberales pero entonces aplicable solo a España puesto que este reglamento impedía el alistamiento de los ciudadanos (que estaban llamados en este régimen a convertirse en los principales defensores de la Constitución) y simplemente convertía las existentes fuerzas de patriotas, urbanos y realistas en nuevos milicianos nacionales.

El asunto, como salta a la vista, provocó vitales alteraciones en la estructura defensiva de la última y constitucional

53 Fechado en Madrid, el 24 de octubre de 1820. AGN, IV, c. 3089, exp. 18. 
Nueva España de 1820 y sin duda incidió de muchos modos en el movimiento trigarante de 1821. Simplemente tomemos en cuenta que el proyecto de milicia nacional trastocaba la existencia y el sostenimiento de lo que según los informes oficiales y los cálculos historiográficos constituía más de la mitad de las fuerzas armadas disponibles: si entre expedicionarios, ejército fijo y milicias provinciales había cerca de 40000 elementos, las milicias urbanas y rurales de patriotas y fieles realistas rebasaban los 44000 . A esa dispersa pero mayoritaria fuerza miliciana iba dirigida la nueva reglamentación y en su implementación o en su obstrucción pudo estribar el éxito del independentismo iturbidista.

\section{CONCLUSIONES}

Hace casi 20 años Guadalupe Jiménez Codinach exhortaba a los historiadores de la independencia a desterrar nombres y calificativos anacrónicos para recuperar, historizándolas, las denominaciones originales. ${ }^{54}$ Una de las intenciones de este artículo tiene que ver con ese afán por problematizar los términos históricos y las categorías historiográficas. Desentrañar los usos e implicaciones del término realista y hacer visibles a los realistas como fenómeno miliciano concreto fueron los dos objetivos primordiales de las reflexiones aquí presentadas.

No pretendo que la historiografía destierre el uso del término realista, pretensión que no solo sería estéril sino también absurda pues en la medida en que una categoría historiográfica resulta explicativa es útil. Empero, juzgo

54 Jiménez Codinach, “La insurgencia de los nombres”, pp. 103-122. 
sumamente beneficioso desmontar modelos o imágenes simplistas que nublan la comprensión de realidades históricas complejas y creo que "ejército realista” es una de esas imágenes perniciosas porque reduce a su mínima expresión un universo social y político tremendamente diverso. No solo el sintagma fue de uso por completo excepcional y ambiguo durante los años de la independencia sino que, como apunta Anthony McFarlane "no existía un solo cuerpo de fuerzas imperiales que pudiera desplegarse en cualquier punto del imperio, ni existía tampoco unidad de mando sobre las fuerzas coloniales", ${ }^{55}$ afirmación que se hizo patente con el repaso de la diversidad de cuerpos milicianos surgidos a lo largo de los años del conflicto.

Si de unos lustros a esta parte la historiografía especializada, apoyada en el estudio de la cultura y los lenguajes políticos, ha logrado desmontar, por ejemplo, la simpleza tradicional de la "máscara de Fernando VII" para restituir la complejidad y la diversidad de opciones políticas que se abrieron con el vacío de poder generado por la crisis de la monarquía, parece entonces que estamos en condiciones de desmontar la creencia de que todo lo "realista" fue siempre unívoco y homogéneo.

Como dejaron entrever las líneas anteriores, queda mucho por explicar respecto al mundo de las fuerzas armadas novohispanas, en general, y el de las milicias en particular. Coincido plenamente con José Javier Ruiz Ibáñez cuando señala que "no ha habido un interés excesivo hacia las fuerzas no profesionales y su significación política” y que dicho déficit historiográfico podría deberse, en parte, a la "pluralidad

55 McFarlane, “Los ejércitos”, p. 240. 
nominativa" y a la "compleja tangibilidad documental de las milicias locales". ${ }^{56}$ Tener claridad sobre la aparición, uso y proliferación de los nombres puede ayudar a explicar la incidencia de los cuerpos milicianos y el desarrollo de ciertas políticas militares. En este sentido el análisis dejó ver que, si bien las denominaciones ya existían en la terminología militar hispánica, hubo etapas milicianas más o menos diferenciadas en el contexto de la crisis política de la monarquía y la guerra estallada en la Nueva España. Así, con la llegada de las noticias de la crisis en 1808, el gobierno del virrey Iturrigaray fomentó la formación de cuerpos de voluntarios de Fernando VII. El estallido de la revolución de 1810 propició que Venegas impulsara la creación de cuerpos de patriotas distinguidos o patriotas y, al año siguiente, el Plan Calleja promovió el surgimiento de cuerpos urbanos. Ninguno de los proyectos anuló al anterior, más bien da la impresión de que se fueron sumando o imbricando con la intención (y necesidad) creciente de consolidar la estructura miliciana para hacer frente a la guerra. De esta forma no es de extrañar que haya persistido el uso de casi todas las denominaciones, pero es incuestionable que predominó a partir de 1815 la de realistas o fieles realistas. No quedan dudas de que dentro de las fuerzas armadas (ya militares, ya milicianas) y en las instancias de gobierno, así como en todo tipo de documentación oficial hubo un escrupuloso rigor en el uso de los términos que en ningún caso confundía al urbano, patriota o realista con el miliciano provincial y menos aún con el militar veterano o de línea. En ese ámbito y en ese contexto bien circunscrito no me queda duda alguna de

${ }^{56}$ Ruiz Ibañez, Las milicias del rey, p. 11. 
que realista aludió a un tipo bien preciso de cuerpo miliciano, dotado de atribuciones, oficialidad y tropa particulares. Creo, en esa medida, que los historiadores debemos ser conscientes y consecuentes con dicho rigor nominativo. Un uso preciso de la terminología militar (grados, empleos, armas, contingentes) ayudará a restituir la complejidad de las fuerzas armadas virreinales que tan presente tenían los involucrados y que con tanta profusión quedó plasmada en la abundante documentación.

Bien dice el citado Ruiz Ibáñez que cada milicia deja ver un peculiar modo de entender el vínculo entre soberano y súbdito y una manera particular de organización local y del ejercicio de la soberanía. En ese marco concreto, realistas hubo y su papel fue muy relevante. Tengo la intuición de que es justo ahí, en esa "clase" de los realistas (y antes en los voluntarios, patriotas y urbanos), en donde mejor se pueden estudiar las incidencias que la guerra ocasionó en los grupos populares. La falta de cuidado en el estudio de estos individuos, que las más de las veces se vieron obligados a tomar las armas para defender sus comunidades bajo las órdenes de oficiales veteranos y que encontraron en la guerra una forma de vida, los ha hecho prácticamente invisibles para las distintas tradiciones historiográficas. ¿Quiénes eran?, ¿qué intereses (políticos, económicos, militares, regionales) tenían en la guerra?, ¿cuál fue su incidencia en los procesos de ruptura y reacomodo de las jerarquías territoriales y en la reconfiguración de las dirigencias locales?, ¿cómo funcionaban las juntas de arbitrios que los sostenían y hasta qué grado las contribuciones resultaban onerosas para los pueblos?, son preguntas que todavía no tienen respuesta nítida y que van de la mano con los planteamientos medulares que 
lanzó Clément Thibaud ${ }^{57}$ para el caso de la guerra bolivariana, pero que muy bien podrían hacerse extensivas a todo conflicto bélico: ¿de qué manera esta forma de guerra es la expresión de una sociedad particular y cómo podemos descifrar el estado de una comunidad por medio de lo militar? Las milicias, en suma y retomando a Ruiz Ibañez, están llamadas a explicar no únicamente evoluciones administrativas o planificaciones gubernamentales, sino también las muy diversas pugnas por el control de la violencia, los acuerdos y los pactos locales, los reclamos de una comunidad armada, los motivos y los sistemas de exclusión (e inclusión) y, en fin, una peculiar cultura política. ${ }^{58}$

Tengo la impresión de que realista como categoría historiográfica y "ejército realista" como monolítico antagonista de la insurgencia han diluido, en suma, a los milicianos que en su momento fueron llamados realistas, es decir, aquellos milicianos que brotan con mayor frecuencia y sistematicidad en la documentación de la época. En consecuencia, parece oportuno recuperarlos como sujetos históricos concretos, como protagónica clase miliciana y como grupo social.

Las tareas no son pocas y no son menores. Creo que debemos buscar mayor precisión y sistematización en el estudio de las fuerzas armadas y lanzarnos a entablar tanto estudios comparativos con otras latitudes hispánicas en las que estos fenómenos ocurrieron, cuanto estudios regionales y de caso que den cuenta detallada de su desarrollo. La riqueza de dichos enfoques se puede ver, por ejemplo, en la diversidad y valía de los análisis con que contamos para

57 Thibaud, “Formas de guerra”, p. 342.

58 Ruiz Ibáñez, Las milicias del rey, p. 34. 
el fenómeno miliciano de las primeras dos décadas de vida independiente.

A riesgo de sonar vertiginosamente anacrónico, considero que en tiempos como los nuestros, en que las policías rurales y las autodefensas se han constituido como actores sociales decisivos en algunas regiones, es nuestra obligación historizar la naturaleza y los muy diversos desarrollos de los fenómenos milicianos, tan palpables a lo largo del conflicto independentista.

\section{SIGLAS Y REFERENCIAS}

AGI, México Archivo General de Indias, fondo México, Sevilla, España.

AGN, IV Archivo General de la Nación, fondo Indiferente Virreinal, Ciudad de México.

Albi, Julio

Banderas olvidadas. El ejército realista en América, Madrid, Ediciones de Cultura Hispánica, 1990.

Alvarado, fray Francisco de

Cartas críticas del Filósofo Rancio, Madrid, Imprenta de E. Aguado, 1811.

Álvarez Cuartero, Izaskun y Julio Sánchez Gómez (eds.)

Visiones y revisiones de la independencia americana. Realismo/Pensamiento conservador: ¿una identificación equivocada?, Salamanca, Ediciones Universidad de Salamanca, 2014.

Archer, Christon I.

El ejército en el México borbónico, 1760-1810, traducción de Carlos Valdés, México, Fondo de Cultura Económica, 1983.

"The Army of New Spain and the Wars of Independence, 1790-1821", en The Hispanic American Historical Review, 61: 4 (nov. 1981), pp. 705-714. 
"Where Did All the Royalists Go? New Light on the Military Collapse of New Spain, 1810-1821”, en Rodríguez O. (ed.), The Mexican, 1989, pp. 24-43.

“'La Causa Buena': The Counterinsurgency Army of New Spain and the Ten Years' War", en Rodríguez O. (ed.), The Independence, 1989, pp. 85-108.

"En busca de una victoria definitiva: el ejército realista en Nueva España, 1810-1821”, en Terán y Serrano (eds.), 2002, pp. 423-238.

Artola, Miguel

La España de Fernando VII, Madrid, Espasa Calpe, 1999.

Ávila, Alfredo y Pedro Pérez Herrero (comps.)

Las experiencias de 1808 en Iberoamérica, México, Universidad de Alcalá, Universidad Nacional Autónoma de México, 2008.

Ávila, Alfredo y Rodrigo Moreno

"Patria-México/Nueva España”, en Fernández Sebastián (dir.), 2014, pp. 153-164.

Benavides Martínez, Juan José

De milicianos del rey a soldados mexicanos. Milicias y sociedad en San Luis Potosí (1767-1824), Madrid, Consejo Superior de Investigación Científica, Universidad de Sevilla, Diputación de Sevilla, 2014.

Chust, Manuel y Juan Marchena (eds.)

Las armas de la nación. Independencia y ciudadania en Hispanoamérica (1750-1850), Madrid, Iberoamericana Vervuert, 2007.

Elsolo por eso

El solo por eso. Canción realista americana con acompañamiento de piano forte y guitarra dedicada por el editor al Exmo. señor coronel general de voluntarios realistas, Madrid [1824]. 
Fernández Sebastián, Javier

"La crisis de 1808 y el advenimiento de un nuevo lenguaje político. ¿Una revolución conceptual?”, en Ávila y PÉrez Herrero (comps.), 2008, pp. 105-133.

“Cómo clasificamos a las gentes del pasado? Categorías sociales e identidades en el tiempo", en Fernández Sebastián y Suárez Cabal (eds.), 2015, pp. 115-139.

Fernández Sebastián, Javier (dir.)

Diccionario político y social del mundo iberoamericano. La era de las revoluciones, 1750-1850 [Iberconceptos-I], Madrid, Fundación Carolina, Sociedad Estatal de las Conmemoraciones Culturales, Centro de Estudios Políticos y Constitucionales, 2009.

Diccionario politico y social del mundo iberoamericano. Conceptos fundamentales, 1770-1870 [Iberconceptos-II], t. 8. Patria, Georges Lomné (ed.), Madrid, Universidad del País Vasco, Centro de Estudios Políticos y Constitucionales, 2014.

Fernández Sebastián, Javier y Juan Francisco Fuentes (dirs.)

Diccionario político y social del siglo XIX español, Madrid, Alianza, 2003.

Fernández Sebastián, Javier y Cecilia Suárez Cabal (eds.)

La subversión del orden por la palabra. Tiempo, espacio e identidad en la crisis del mundo ibérico, siglos XVIII-XIX, Bilbao, Universidad del País Vasco, 2015.

Frasquet, Ivana (coord.)

Bastillas, cetros y blasones. La independencia en Iberoamérica, Madrid, Fundación Mapfre, 2006.

García Godoy, María Teresa

Las Cortes de Cádiz y América. El primer vocabulario liberal español y mejicano (1810-1814), Sevilla, Diputación de Sevilla, 1998. 


\section{Gil Novales, Alberto}

Las sociedades patrióticas (1820-1823). Las libertades de expresión y de reunión en el origen de los partidos políticos, Madrid, Tecnos, 1975, 2 volúmenes.

Guerra, José [Servando Teresa de Mier]

Historia de la revolución de Nueva España..., Londres, Imprenta de Guillermo Lindon, 1813, 2 volúmenes.

Gutiérrez G., José Antonio

El gobierno de frontera de San Luis Colotlán y sus milicias en la colonia, Guadalajara, Universidad Autónoma de Aguascalientes, Municipio de Colotlán, Centro Universitario del Norte, Universidad de Guadalajara, 2010.

Guzmán Pérez, Moisés

"Chaquetas, insurgentes y callejistas. Voces e imaginarios en la independencia de México”, en Hébrard y Verdo (eds.), 2013, pp. 135-149.

Hamnett, Brian R.

Raíces de la insurgencia en México. Historia regional 17501824, traducción de Agustín Bárcena, México, Fondo de Cultura Económica, 1990.

Revolución y contrarrevolución en México y el Perú. Liberales, realistas y separatistas (1800-1824), traducción de Roberto Gómez Ciriza, México, Fondo de Cultura Económica, 2011.

Hébrard, Véronique y Geneviève Verdo (eds.)

Las independencias hispanoamericanas. Un objeto de historia, Madrid, Casa de Velázquez, 2013.

Hernández Galicia, Jesús Fidel

"Guerra sanguinaria y previsión política. La construcción del sistema contrainsurgente de José de la Cruz (1810-1813)", tesis de licenciatura en historia, México, Universidad Nacional Autónoma de México, 2011. 
Hernández y Dávalos, Juan E.

Colección de documentos para la historia de la Guerra de Independencia de México de 1808 a 1821, edición en CD, dirección y presentación de Alfredo Ávila y Virginia Guedea, México, Universidad Nacional Autónoma de México, 2010.

Hocquellet, Richard

"Nombrar al enemigo: luchas políticas y guerras civiles, España, 1808-1823”, en La revolución, 2011, pp. 261-270.

Jiménez codinach, Guadalupe

“La insurgencia de los nombres”, en VÁzQuez (coord.), 1997, pp. 103-122.

KaHLE, Günter

El ejército y la formación del Estado en los comienzos de la independencia de México, traducción de María Martínez Peñaloza, México, Fondo de Cultura Económica, 1997.

Kuethe, Allan J.

"Las milicias disciplinadas en América", en Kuethe y MarCHENA F. (eds.), 2005, pp. 101-126.

Kuethe, Allan J. y Juan Marchena F. (eds.)

Soldados del Rey. El ejército borbónico en América colonial en vísperas de la Independencia, Castelló de la Plana, Publicacions de la Universitat Jaume I, 2005.

La Parra, Emilio

Los Cien Mil Hijos de San Luis. El ocaso del primer impulso liberal en España, Madrid, Síntesis, 2007.

La revolución

La revolución, la política moderna y el individuo. Miradas sobre el proceso revolucionario en España (1808-1835), Zaragoza, Prensas Universitarias de Zaragoza, Universidad de Cádiz, 2011. 
Lemoine, Ernesto

Morelos. Su vida revolucionaria a través de sus escritos y de otros testimonios de la época, México, Universidad Nacional Autónoma de México, 1991.

Luqui-Lagleyze, Julio Mario

"Por el rey, la fe y la patria." El ejército realista del Perú en la independencia sudamericana, 1810-1825, Madrid, Ministerio de Defensa, 2006.

Luqui-Lagleyze, Julio Mario y Antonio Manzano Lahoz

"Los realistas" (1810-1826). Virreinatos del Perú y del Río de la Plata, y Capitanía General de Chile, Valladolid, España, Quirón ediciones, 1998.

Marchena Fernández, Juan (coord.)

El ejército de América antes de la independencia. Ejército regular y milicias americanas, 1750-1815. Hojas de servicio $y$ uniformes, edición en disco compacto, Madrid, Fundación Mapfre Tavera, 2005.

McAlister, Lyle N.

El fuero militar en la Nueva España (1764-1800), traducción de José Luis Soberanes, México, Universidad Nacional Autónoma de México, 1982.

McFarlane, Anthony

"Los ejércitos coloniales y la crisis del imperio español, 18081810”, en Historia Mexicana, Lviri:1 (229) (jul.-sep. 2008), pp. $229-285$.

Mendoza MuÑoz, Jesús

Los dragones provinciales de Sierra Gorda en Querétaro durante la Guerra de Independencia de México, Querétaro, Fomento histórico y cultural de Cadereyta, 2010. 
Meseguer, Mariano

Himno Realista con orquesta á tres voces Dedicado al Soverano de las Españas Don Ferndo. $7^{\circ}$ Nuestro Rey y Señor. Por el Presbitero Dn Mariano Meseguer Contralto de su Rl. Capilla, Madrid, 1824.

Morelli, Federica

"¿Disciplinadas o republicanas? El modelo ilustrado de milicias y su aplicación en los territorios americanos (1750-1826)", en Ruiz IbÁÑ̃z, (coord.), 2009, pp. 417-436.

Moreno Gutiérrez, Rodrigo

"Las fuerzas armadas en el proceso de consumación de independencia: Nueva España, 1820-1821", tesis de doctorado en historia, México, Universidad Nacional Autónoma de México, 2014.

Oñate Algueró, Paloma de

Servir al Rey. La milicia provincial (1734-1846), Madrid, Ministerio de Defensa, 2003.

Ortiz Escamilla, Juan

Guerra y gobierno. Los pueblos y la independencia de México, $2^{a}$ edición corregida y aumentada, México, El Colegio de México, Instituto de Investigaciones Dr. José María Luis Mora, 2014.

Ortiz Escamilla, Juan (coord.)

Fuerzas militares en Iberoamérica, siglos XVIII y XIX, México, El Colegio de México, El Colegio de Michoacán, Universidad Veracruzana, 2005.

Pérez Garzón, Juan Sisinio

Milicia nacional y revolución burguesa. El prototipo madrileño, 1808-1874, prólogo de Manuel Espadas Burgos, Madrid, Consejo Superior de Investigación Científica, 1978. 
Pérez Márquez, Ana Lilia

"Milicia urbana: los patriotas voluntarios distinguidos de Fernando VII de la Ciudad de México (1808-1820)", México, tesis de licenciatura en historia, México, Universidad Autónoma Metropolitana-Iztapalapa, 2004.

Pérez Vejo, Tomás

"Un mito historiográfico: españoles realistas contra criollos insurgentes”, en Âlvarez Cuartero y Sánchez Gómez (eds.), 2014, pp. 78-93.

Rodríguez Tapia, Andrea

"Los opositores al movimiento de Miguel Hidalgo. Representaciones e interpretaciones historiográficas, 1810-1852", tesis de licenciatura en historia, México, Universidad Nacional Autónoma de México, 2010.

Rodríguez O., Jaime E. (coord.)

The Independence of Mexico and the Creation of the New Nation, Los Ángeles, Irvine, University of California, Latin American Center Publications, 1989.

The Mexican and Mexican American Experience in the $19^{\text {th }}$ Century, Tempe, Bilingual Press, 1989.

Revolución, independencia y las nuevas naciones de América, Madrid, Mapfre Tavera, 2005.

Ruiz IвÁÑEz, José Javier (coord.)

Las milicias del rey de España. Sociedad, política e identidad en las Monarquias Ibéricas, Madrid, Fondo de Cultura Económica, Red Columnaria, 2009.

SÁnchez Gómez, Julio

"La independencia de la República Oriental del Uruguay: los realistas en la Banda Oriental”, en Frasquet (coord.), 2006, pp. 57-92. 
Semprún, José y Alfonso Bullón de Mendoza

El ejército realista en la independencia americana, Madrid, Mapfre, 1992.

Serrano Ortega, José Antonio

Jerarquía territorial y transición política. Guanajuato. 17901836, Zamora y México, El Colegio de Michoacán, Instituto de Investigaciones Dr. José María Luis Mora, 2001.

Terán, Marta y José Antonio Serrano (coords.)

Las guerras de independencia en la América española, Zamora, Mich., El Colegio de Michoacán, Instituto Nacional de Antropología e Historia, Universidad Michoacana de San Nicolás de Hidalgo, 2002.

Thibaud, Clément

"Formas de guerra y mutación del ejército durante la guerra de la independencia en Colombia y Venezuela", en Rodríguez O. (coord.), 2005, pp. 339-364.

Torrente, Mariano

Historia de la Independencia de México, ed. facsimilar, presentación y notas de Ernesto de la Torre Villar, México, Universidad Nacional Autónoma de México, Miguel Ángel Porrúa, 1989.

VÁzquez, Josefina Zoraida (coord.)

Interpretaciones sobre la Independencia de México, México, Nueva Imagen, 1997.

Vinson III, Ben

Bearing Arms for His Majesty. The Free-Colored Militia in Colonial Mexico, Stanford, Stanford University Press, 2001. 